Review Article

\title{
In vitro Characterisation of Endophytic Fungi Strains from Lantana camara Leaves Displaying Antifungal Activity Against Phytophthora colocasiae
}

\author{
Mbouobda Hermann Desire ${ }^{1,2, ~ *, ~ M u y a n g ~ R o s a l i n e ~ F o r s a h ~}{ }^{1}$, Djeuani Astride Carole ${ }^{2,3}$, \\ Djou Tchinda Ismael ${ }^{1}$, Fotso ${ }^{1}$ \\ ${ }^{1}$ Department of Biology, University of Bamenda, Bamenda, Cameroon \\ ${ }^{2}$ Department of Biological Sciences, University of Yaoundé I, Yaoundé, Cameroon \\ ${ }^{3}$ Department of Plant Biology, University of Yaoundé I, Yaoundé, Cameroon
}

Email address:

mbouobda@yahoo.fr(M. H. Desire), mbouobdah@gmail.com(M. H. Desire), wanfosah3@yahoo.fr(M. R. Forsah), djeuani.uyi@hotmail.com (D.A. Carole), ismaeldjou@yahoo.fr(D. T. Ismael), fotsober@gmail.com (Fotso)

${ }^{*}$ Corresponding author

\section{To cite this article:}

Mbouobda Hermann Desire, Muyang Rosaline Forsah, Djeuani Astride Carole, Djou Tchinda Ismael, Fotso. In vitro Characterisation of Endophytic Fungi Strains from Lantana camara Leaves Displaying Antifungal Activity Against Phytophthora colocasiae. Journal of Diseases and Medicinal Plants. Vol. 5, No. 6, 2019, pp. 87-93. doi: 10.11648/j.jdmp.20190506.11

Received: August 31, 2019; Accepted: October 4, 2019; Published: November 21, 2019

\begin{abstract}
Colocasiae esculenta is an important tropical tuber crop susceptible to attack by many diseases. The most devastative among these is Taro leaf blight cause by the pathogen Phytophthora colocasiae. The pathogen can cause rapid complete defoliation and crop destruction and under some circumstances, the disease can attack harvested corms and cause heavy losses during storage. Endophytes constitute an important source of bioactive secondary metabolites and enzymes. Based on their phytochemical properties, they can be used as a source of antifungal agent for the treatment of some infectious diseases. In order to evaluate the impact of endophytes on plant defence, in vitro evaluation of the growth effect of endophytic fungi against $P$. colocasiae was conducted in dual culture, after isolating and screening endophytic fungi from $L$. camara leaves for their production of some extracellular enzymes (amylases, lipases, laccases, protease and cellulose) and some secondary metabolites (tannins, saponins, phenols, cardiac glycoside) using standard procedures. In-vitro culture techniques with Potato Dextrose Agar (PDA) as culture medium were used to isolate endophytes from L. camara leaf tissues. Isolate identification was done using macroscopic and microscopic characteristics. These isolates were then tested in vitro to evaluate their morphological growth effect against $P$. colocasiae via the dual culture. Five endophytic fungi were isolated from Lantana camara leaves and coded $\mathrm{L}_{1}, \mathrm{~L}_{2}, \mathrm{~L}_{3}, \mathrm{~L}_{4}$ and $\mathrm{L}_{5}$. The $\mathrm{L}_{2}, \mathrm{~L}_{3}$ and $\mathrm{L}_{5}$ strains were filamentous and showed coenocytic hyphae which bore some structures' called conidiosphores identified as Cladosporium sp. $\mathrm{L}_{1}$ strain was filamentous fungi having clamp connections hyphae (bridge-like growth) above hyphal septa and brown sclerotia. $\mathrm{L}_{4}$ strain showed very tiny interwoven and tightly parked mycelia. As enzyme activities, all the strains were found to produce amylase and not protease. $L_{1}, L_{3}$ and $L_{4}$ were able to synthesis laccase while $\mathrm{L}_{5}$ produced cellulose and lipase. For the secondary metabolites, all the strains were able to produced tannins and cardiac glycoside but they did not synthesis saponins. $\mathrm{L}_{1}, \mathrm{~L}_{2}$ and $\mathrm{L}_{4}$ strains were able to produced phenol. In dual culture, the growth of the pathogen decreased the growth rate of the endophytes. $\mathrm{L}_{2}$ strain grew normally by forming an arc around $P$. colocasiae growth while $\mathrm{L}_{3}$ and $\mathrm{L}_{5}$ strains induced the pathogen to grow on the opposite side of $P$. colocasiae. Concerning $\mathrm{L}_{1}$ and $\mathrm{L}_{4}$ strains, there were no effect. Based on the antifungal activities against $P$ colocasiae, these strains $\mathrm{L}_{2}$ and $\mathrm{L}_{3}$ could be used for biological control of taro life blight.
\end{abstract}

Keywords: Lantana camara, Clasdosporium sp., Phenol, Laccase, Phytophthora colocasiae 


\section{Introduction}

Colocasiae esculenta (Taro) is an important tuber crop that grow in the tropical area which is used as a staple food or subsistence by world's population particularly in Africa precisely in Cameroon. Taro corms, cormels, leaves, and petioles are used as vegetable and considered as a rich source of water, carbohydrates, proteins, minerals, and vitamins [1]. There is a significant production decline of this crop due to attack by pathogens. The local farmers are facing a decrease in productivity due its attack by many pathogens such as viruses, bacteria, nematodes and fungi. Among's these pathogens, the most important is the fungi called Phytophthora colocasiae [2]. This pathogen can cause rapid complete defoliation and crop destruction. Under certain circumstances, the disease can attack harvested corms, cormels and cause heavy losses during storage.

P. colocasiae is the main phytopathogenic oomycete that causes leaf blight and corm rot on taro (Colocasia esculenta). It occurs under humid conditions and densely planted fields. Taro leaf blight is thus spread almost exclusively by sporangia Dissemination via rain splash is the most common dispersal mechanism. Spread of the fungus within a taro planting occurs when sporangia and zoospores are splashed from infected to healthy leaves [3]. Therefore, the use of synthetic fungicide by the farmers become necessary. These synthetic compounds have the potential harmful effects on the environment as well as on human health. The increasing public demands for reduction in pesticides used emphasizes the need for alternative disease control strategies. The new strategy is biology control using antagonist fungi susceptible to the dissemination of pathogen such as endophytic fungi [4]. Endophytes are organisms inhabiting plant organs that at some time in their life can colonize internal plant tissues without causing apparent harm to the host. The endophytic fungi have been shown to exhibit plant growth and health promoting effects when applied to the seed and seedling prior to exposure to plant parasites [5]. Its principal effect is related to their ability to produce secondary metabolites (phenol, saponins, tannins, cardiac glycosides), antibiotics as well as lytic enzymes (lipase, protease, laccase, amylase, cellulase) [6-7] which help increase the yield of productivity. These endophytes are more present in plants encounter in our environment. Among these plants, we can have eucalyptus and herbaceous plants such as lantana camara. Lantana camara is used as a fence in some localities and have many therapeutic properties due to the presence of natural agents [8].

Biological control of plant disease is a viable alternative which make use of microorganisms to control the propagation of pathogen and treatment of the diseases. Biological control agents antagonize pathogens directly by hyperparasitism, predation, and production of antibiotics and lytic enzymes; and indirectly by competing for space, nutrients and inducing systemic resistance [9]. Several endophytes have been shown to be effective against many pathogens [10]. However, commercial biocontrol agents for the management of $P$. colocasiae are needed. One of the solutions proposed in this study is plant biological management which is based on using endophytes especially fungi, in controlling taro leaf blight. Thus, this study was carry out to investigate in vitro the growth effect of endophytic fungi isolated from Lantana camara leaves against $P$. colocasiae the causative agent of Taro leaf blight.

This work consisted of the isolation, purification and identification of endophytic fungi from Lantana camara leave; screening of the isolated endophytic fungi for the production of some secondary metabolites and some enzymes and to evaluate in vitro the growth effect of endophytic fungi against $P$. colocasiae in co-culture.

\section{Materials and Methods}

\subsection{Isolation of Endophytic Fungi}

The leaves of L. camara were cut randomly, washed with distilled water, then cut in to pieces using a blade and surface sterilised by immersion of Sodium hypochlorite $(\mathrm{NaOCl})$ followed with $95 \%$ ethanol for $1 \mathrm{~min}$. These pieces of leaves were then sterilised in series with $70 \%(\mathrm{v} / \mathrm{v})$ ethanol for 1 minute, $10 \%(\mathrm{v} / \mathrm{v}) \mathrm{NaOCl}$ for 30 seconds and then cleaned by passing through two sets of sterile distilled water. The sterile samples were placed on sterilised Petri dishes containing Potato Dextrose Agar (PDA) media and ampicillin (0.01\%). The petri dishes were then sealed with parafilm paper and incubated at $28 \pm 2^{\circ} \mathrm{C}$. The plates were observed each day from the second to the fifth day. During purification, a new PDA media was prepared and the strains growing during the step of isolation were transferred to the new media in aseptic conditions. The medium was then incubated at $28 \pm 2{ }^{\circ} \mathrm{C}$ during 4 days. The process was repeated until the pure strains were obtained.

\subsection{Identification of Endophytic Fungi}

For morphological characterisation, mycelia of each endophyte strain were mounted on the microscope slides. Endophytic fungi isolates were identified based on the morphological feature such as the colour of the isolate, ramification of the hyphae and the present of spores. The morphological observation was performed with naked eye and by using a light microscope at 20X magnification (Optic Ivymen system) and the photographs taken using a digital camera magnified at 7.1 mega pixels. In cryptic morphological identification, photos of the endophytes were compared with those already identified [11].

\subsection{Phytochemical Screening of Endophytic Fungi}

\subsubsection{Test of Tannin}

The mycelia extract was treated with alcoholic iron trichloride $\left(\mathrm{FeCl}_{3}\right)$ reagent. A bluish black colour, which disappeared upon the addition of a little dilute sulphuric acid $\left(\mathrm{H}_{2} \mathrm{SO}_{4}\right)$ followed by the formation of a yellowish brown 
precipitate indicated the presence of tannins.

\subsubsection{Test of Phenols}

The extract was dissolved in $5 \mathrm{ml}$ distilled water and a few drops of $\mathrm{FeCl}_{3}$ were added and a dark green coloration shows the presence of phenols.

\subsubsection{Test of Saponins}

The crude extract of the mycelia was measured and placed in to sterilized test tubes containing $5 \mathrm{ml}$ of water. They were shaken vigorously and allows standing for $10 \mathrm{~min}$. No froth indicates the absence of saponines and the presence of a stable froth indicates the present of saponins.

\subsubsection{Test of Cardiac Glycosides}

The mycelia extract was mixed with $1 \mathrm{ml}$ of $\mathrm{FeCl}_{3}$ reagent (a mixture of 1 volume of $5 \% \mathrm{FeCl}_{3}$ solution and 99 volumes of glacial acetic acid) and a few drops of concentrated $\mathrm{H}_{2} \mathrm{SO}_{4}$ to the solution was added and then observed. The appearance of a greenish blue colour within a few minutes indicated the presence of cardiac glycosides.

\subsection{Endophytic Fungi Screening for Extracellular Enzymes Activities}

Screening of fungal extracellular enzymes typically involved growth on specific indicative media [12]. Endophytes were assessed by growing them on GYP and PDA media with dissolved substrates. After incubation for 3-7 days at room temperature, the zone of enzyme activity surrounding the fungal colony was observed.

\subsubsection{Amylolytic Activity}

Amylase activity was assessed by growing the fungi on Glucose Yeast Extract Peptone Agar (GYP) medium composed of glucose $(0.15 \mathrm{~g})$, yeast extract $(0.1 \mathrm{~g})$, peptone $(0.5 \mathrm{~g})$, agar $(02.4 \mathrm{~g})$, distilled water (1litre) and $0.2 \%$ soluble starch $\mathrm{pH}$ 6.0. After incubation for 5 days the plates were flooded with $1 \%$ iodine in $2 \%$ potassium iodide and observed.

\subsubsection{Lipolytic Activity}

For lipase activity, the fungi were grown on Peptone Agar medium (peptone $10 \mathrm{~g}, \mathrm{NaCl} 5 \mathrm{~g}, \mathrm{CaCl}_{2} .2 \mathrm{H}_{2} \mathrm{O} 0.1 \mathrm{~g}$, agar- $16 \mathrm{~g}$, distilled water-1L; $\mathrm{pH}$ 6.0) supplemented with Tween 20 separately sterilized and added $1 \%$ to the medium. At the end, the petri dishes were incubated for 5 days and a visible precipitate around the colony due to the formation of calcium salts of the lauric acid liberated by the enzyme shows a positive activity.

\subsubsection{Proteolytic Activity}

The fungi were grown in Glucose Yeast Extract Peptone Agar medium with $0.4 \%$ gelatine $(\mathrm{pH} 6.0$ ) was used. $8 \%$ of gelatine solution in water was sterilized separately and added to GYP medium at the rate of $5 \mathrm{~mL}$ per $100 \mathrm{~mL}$ of medium. After incubation of 5 days, the plates were observed.

\subsubsection{Laccase Activity}

The fungi were grown in petri dishes contained Glucose Yeast Extract Peptone Agar medium supplemented with $0.05 \mathrm{~g}$ $\alpha$-napthol $\mathrm{L}^{-1}, \mathrm{pH} 6.0$ was used. The petri dishes were incubated and as the fungus grew the colourless medium turned blue due to oxidation of $\alpha$-napthol by enzyme lacasse.

\subsubsection{Cellullase Activity}

The determination of cellulase activity was performed on nutrient agar containing $0.2 \%$ carboxyl methylcellulose (CMC). Cellulose activity was identified by the appearance of a clear halo zone around the tested strain after treatment with Gram's Iodine.

\subsection{In vitro Effect of Endophytic Fungi Against P. colocasiae}

This was carried out on monoculture and co-culture. The monoculture test was contained respectively the endophytic fungi and $P$. colocasiae independently. In the dual culture, the endophyte and $P$. colocasiae was sown in the same Petri dishes separated with a distance of about $2.5 \mathrm{~cm}$. The PDA media was prepared as firstly described.

\subsection{Fugal Pathogen Culture}

The pathogen was isolated from the leave of Colocasiae esculenta and was routinely grown on potato dextrose agar (PDA): Phytophthora colocasiae

\section{Results}

\subsection{Morphological Characterisation}

From the leaves of L. camara, five strains of endophytes were isolated and coded $\mathrm{L}_{1}, \mathrm{~L}_{2}, \mathrm{~L}_{3}, \mathrm{~L}_{4}$ and $\mathrm{L}_{5}$. These fungi strains exhibited colony characteristics that were used to identify the fungi. The microscopic observations revealed that the isolate endophyte $\mathrm{L}_{2}, \mathrm{~L}_{3}$ and $\mathrm{L}_{5}$ were filamentous fungi with coenocytic hyphae which bore some structures called conidiophores. These fungi strains belong to Cladosporium $\mathrm{sp}$. (Figure 1). $\mathrm{L}_{1}$ strain was filamentous fungi having clamp connections hyphae (bridge-like growth) above hyphae septa and brown sclerotia. $\mathrm{L}_{4}$ strain showed very tiny interweaves and tightly parked mycelia (Figure 1).

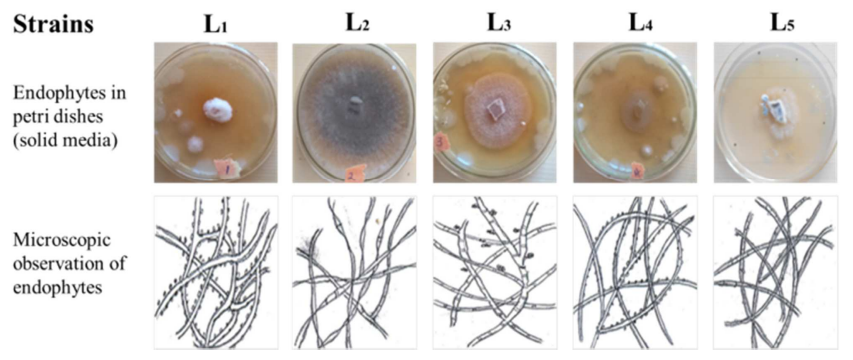

Figure 1. Pure endophytic fungi and microscopic observation.

\subsection{Phytochemical Screening of Crude Extract of Endophytic Fungi}

\subsubsection{Evaluation of Tannins}

The solution containing the mycelia $\mathrm{L}_{1}$ and $\mathrm{L}_{3}$ showed a yellowish green coloration while the solution containing the 
strain $\mathrm{L}_{2}, \mathrm{~L}_{4}$ and $\mathrm{L}_{5}$ was yellowish brown at the level where the mycelia was found, indicated the presence of tannin in the medium (Table 1).

\subsubsection{Evaluation of Phenols}

A reddish brown coloration was obtained upon addition of ferric chloride solution into the test tubes containing $\mathrm{L}_{3}$ and $\mathrm{L}_{5}$ indicated the absence of phenol while a pale yellow coloration was observed in the case of $\mathrm{L}_{1}, \mathrm{~L}_{2}$ and $\mathrm{L}_{4}$ showing the presence of phenol (Table 1)

\subsubsection{Evaluation of Saponins}

For all the strains, no stable froth was observed after addition of water on the mycelia. There was no reaction after shaking and allowing it to stand for 10 minutes. This means that all the strains were not producing saponins (Table 1).

\subsubsection{Evaluation of Cardiac Glycosides}

For all the strains, a yellowish colour was observed when ferric chloride and a few drops of concentrated sulphuric acid were added. This indicates that all the strains were able to synthesise these phytochemicals (Table 1).

Table 1. Summary of phytochemical screening of the five strains of endophytes.

\begin{tabular}{lllll}
\hline Strains & Tannins & Phenols & Saponins & $\begin{array}{l}\text { Cardiac } \\
\text { Glycoside }\end{array}$ \\
\hline $\mathrm{L}_{1}$ & + & + & - & + \\
$\mathrm{L}_{2}$ & + & + & - & + \\
$\mathrm{L}_{3}$ & + & - & - & + \\
$\mathrm{L}_{4}$ & + & + & - & + \\
$\mathrm{L}_{5}$ & + & - & - & + \\
\hline
\end{tabular}

Key: $+=$ positive test, $-=$ negative test

\subsection{Screening of Endophytic Fungi for Extracellular Enzymes Activities}

\subsubsection{Amylolytic Activity}

Iodine/potassium was the principal tracer that reacted with the culture medium of all the colonies by turning it into dark brown/black leaving the zone around the hyphae of the fungi colony yellowish (Table 2).

\subsubsection{Laccase Activity}

As the fungi grew (after four days of incubation) the culture medium remained translucent. But the zone around the fungi colony of the strain $\mathrm{L}_{1}, \mathrm{~L}_{3}$ and $\mathrm{L}_{4}$ turned into dark-purple indicating the syntheses of the enzyme laccase by the endophytes while the surrounding of the strain $\mathrm{L}_{2}$ and $\mathrm{L}_{5}$ remained translucent (Table 2).

\subsubsection{Cellulase Activity}

After five days of incubation, the plate was sprayed with iodine. A clear halo zone was observed around the colony of the fungi of the strain $\mathrm{L}_{5}$ indicated the presence of cellulase, while the strains $\mathrm{L}_{1}, \mathrm{~L}_{2}, \mathrm{~L}_{3}$ and $\mathrm{L}_{4}$ remained translucent indicating the absence of cellulase (Table 2).

\subsubsection{Lipolytic Activity}

The lipolytic activity was characterised by the visible precipitate around the colony of $\mathrm{L}_{5}$, while the surrounding of the colonies in plates containing the strains $\mathrm{L}_{1}, \mathrm{~L}_{2}, \mathrm{~L}_{3}$ and $\mathrm{L}_{4}$ had no reaction (Table 2).

\subsubsection{Proteolytic Activity}

With the addition of aqueous ammonium sulphate after 4 days of incubation, there was no reaction or change on the culture medium and the zone around the colony (Table 2).

Table 2. Summary of enzyme activities of the five strains of endophytes.

\begin{tabular}{llllll}
\hline Strain & Amylolytic Activity & Laccase Activity & Cellulase Activity & Lipolytic Activity & Proteolytic Activity \\
\hline $\mathrm{L}_{1}$ & + & + & - & - & - \\
$\mathrm{L}_{2}$ & + & - & - & - & - \\
$\mathrm{L}_{3}$ & + & + & - & - & - \\
$\mathrm{L}_{4}$ & + & + & - & - & - \\
$\mathrm{L}_{5}$ & + & - & + & + & - \\
\hline
\end{tabular}

Key: $+=$ positive result, $-=$ negative result

\subsection{Morphological Growth Effect of Endophytic Fungi Against P. colocasiae}

In the dual culture media, $P$. colocasiae grew very slowly compared to the control. In co-culture media of $P$. colocasiae and endophyte, the endophytic fungi grew faster than the pathogen. After 5 days of incubation, the growth of the endophytes and $P$. colocasiae on the dual media were compared with their growth on the monoculture. The stain $\mathrm{L}_{1}$ on their nature had a slow growth rate (Figure 2. $\mathrm{L}_{1} \mathrm{~B}$ ). In the co-culture, the rate of growth of the strain $\mathrm{L}_{1}$ was the same but that of the pathogen was lower (Figure 2. $\mathrm{L}_{1}$ ). The strain $\mathrm{L}_{2}$ was growing at the same rate on co-culture (Figure $2 . \mathrm{L}_{2} \mathrm{C}$ ) as on the monoculture but by forming an arc around the pathogen which the growth was very slow (Figure $2 . \mathrm{L}_{1} \mathrm{~B}$ ). The strains of endophytes $\mathrm{L}_{3}$ growth rate in the dual culture was slow compared to its monoculture; but $P$. colocasiae was like growing on the opposite site of the endophyte (Figure 2. $\mathrm{L}_{3} \mathrm{C}$ ). The strain $\mathrm{L}_{4}$ had the same growth rate but the growth of the endophyte $\mathrm{L}_{4}$ affected the growth of the pathogen. For instance, the growth of the endophyte did not affect the growth of the pathogen (Figure $2 . \mathrm{L}_{4} \mathrm{C}$ ). Moreover the strain $\mathrm{L}_{5}$ were growing on the opposite side of $P$. colocasiae and the rate of growth of $P$. colocasiae was very slow compared to its monoculture (Figure $2 . \mathrm{L}_{5}$ ). $\mathrm{L}_{1}$ and $\mathrm{L}_{4}$ were growing normally in such a way that the growth did not affect the growth of the pathogen and vice versa. 


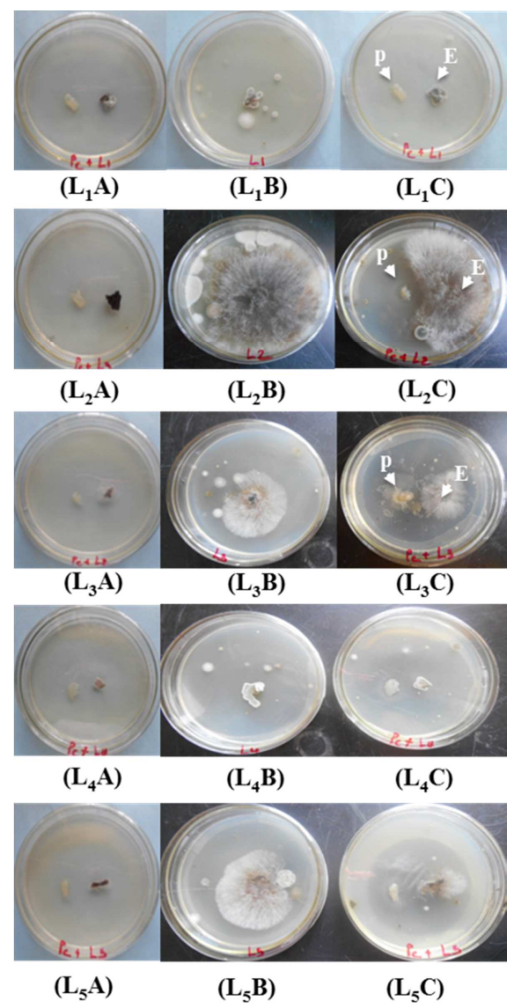

Figure 2. Morphological growth of endophytes and P. colocasiae in the PDA media: (Lx A) co-culture of day zero ( $L x B$ ) monoculture of endophytes and (Lx C) co-culture (pathogen on the left and endophytes on the right). In petri dish P. colocasiae $(P)$ and endophytes $(E)$.

\section{Discussion}

After isolation and purification, five strains of endophytic fungi were obtained from the leaves of L. camara. This suggested that endophytic fungi are ubiquitous and have been found in all plant species especially vascular plants and grasses examined to date [13-5]. Due to the fact that the strains $\mathrm{L}_{2}, \mathrm{~L}_{3}$ and $\mathrm{L}_{5}$ produced spores that were linked as a chain, cylindrical and unicellular, their mycelia presented coenocytic hyphae which bore a structure call conidiosphores, there could be referred to the Cladosporium sp. Cladosporium sp was one of the most isolated species obtained during the isolation of endophytic fungi from leaves of L. camara [14].

Furthermore, phytochemical screening of the strains isolated from $L$. camara revealed that endophytic fungi are able to produce some metabolites. All the five strains revealed the presence of cardiac glycoside and tannins. $\mathrm{L}_{1}, \mathrm{~L}_{3}$ and $\mathrm{L}_{4}$ showed the presence of phenols, while $\mathrm{L}_{3}$ and $\mathrm{L}_{5}$ revealed negative for phenol, whereas all the strains revealed the absence of saponins. Endophytic fungi are sources of bioactive metabolites with tannins, phenols and cardiac glycoside compounds being examples [7]. Moreover, the ability of endophytes to produce some metabolites and not some has been described [15]; where different endophytes in a plant may produce different secondary metabolites. Hence, endophytes play different functions in the plant and the total number of metabolites in plant extracts may be a contribution of all endophytes that live in the plant. The available secondary metabolites, having anti-pathogenic properties and their roles in plant defence have been elaborated in the works of [16-17]. In addition, the detection of secondary metabolites from L. camara and from other medicinal plants in general, as well as their antimicrobial properties depends on the method used [18].

The principal function of fungal enzymes is to hydrolyse food substances or their involvement in defence against pathogen. Lytic enzymes such as amylase, proteinase, lipase and cellulase have been proven to antagonize pathogenic fungi via competition for tissues nutrients, hence suppressing plant pathogens [7]. The capability of endophytes to produce different enzymes should have an important role in host defence, since they do not destroy the host living tissue. These degrading enzymes are important factors affecting the lifestyle of endophytes in becoming antimicrobial.

The yellowish colour observed around the entire fungi colony of all strains studied revealed that the starch in the medium was digested by the enzyme amylase produced by the fungi. Thus this result is in line with that of [19] who reported that most endophytes produced amylase for starch hydrolyses in plants. Moreover, $\mathrm{L}_{1}, \mathrm{~L}_{3}$ and $\mathrm{L}_{4}$ strains indicated the presence of laccase hence the oxidation of alpha-napthol. This strongly ties with the results of [20] who reported that some endophytes are able to produce laccase probably because of the nature of the fungi. Laccases are important enzymes and can participate actively in establishing the pathogenicity process in plants and even directly in the degradation of lignin [7]. The synthesis of cellulose by some endophytic fungi permitted them to degrade cellulose and use as their principal nutrients. Only one strain $L_{5}$ was able to synthesis cellulose. Similar results were reported that the synthesis of cellulases by endophytic fungi extracted from leaf is not really significant [21]. The degradation of lipids by lipase in the medium caused the visible light brown precipitate due to the formation of calcium salts lauric acid liberated by the enzyme. Among all the five strains only the strain $\mathrm{L}_{5}$ expressed extracellular protease activity. Significant lipolytic activities have been reported in most plants [15]. Also a positive protease activity for some endophytic fungi from strains isolated from Piper hispidum [22]. For fungi that have a high growth rate in terms of colony diameter, the clear zones or halos created in the agar plates with the specific substrate might have been masked and thereby preventing detection of the particular enzyme. Thus the lack of a positive result could mean that either the enzyme was not produced, or that it was produced and not released from the mycelium, or that it was produced and released, but the medium inhibited its detection [23]. Thus, the absence of a reaction in agar media is not absolutely confirmed of the inability of a species to produce a particular enzyme.

By making a dual culture of the endophytic fungi isolated from $L$. camara with $P$. colocasiae, the pathogen was having an effect on the growth of the endophytes and vice versa. With the facts that $P$. colocasiae may have an ability to produce some chemicals to conquer their environment before grow, the strain of endophyte $L_{2}$ was able to grow on its own side each, 
having an antagonist growth effect against $P$. colocasiae. The strain $\mathrm{L}_{3}$ grew slowly but was like inducing the pathogen to grow in the opposite side. The monoculture showed high growth rate of endophytic fungi while on the dual culture, the strain $\mathrm{L}_{2}$ inhibited the growth of $P$. colocasiae more than $\mathrm{L}_{3}$. This could be because $\mathrm{L}_{2}$ produced the secondary metabolites phenol with great effect on the growth of $P$. colocasiae as compared to $\mathrm{L}_{3}$ which did not produce phenol. Secondly it could be because the strains $\mathrm{L}_{3}$ produced an enzyme laccase which reduced the growth of $P$. colocasiae compared to the strain $\mathrm{L}_{2}$ which did not produce laccase. Results obtained from the dual culture assays only showed direct antagonism that may be due to the production of antibiotics and/or lytic enzymes produced by endophytes [4].

From the microscopic observation, two difference mechanisms of resistance to the pathogen developed by the endophytes were observed: developing a thick layer around the mycelia and producing spores. Therefore, $\mathrm{L}_{2}+$ and $\mathrm{L}_{3}+$ developed a second layer on their mycelia that help them to resist the pathogen and were identify to belong to Clasdosporium sp. Many species also produce dense aggregations of tissue called sclerotia which help fungi to survive challenging conditions such as freezing, desiccation and microbial attack [24]. Most fungi produce durable microscopic structures such as spores that is important for dispersal and/or survival under adverse conditions. This was the case of $\mathrm{L}_{1}, \mathrm{~L}_{4}$ and $\mathrm{L}_{5}$ which entered into the dormancy phase by producing spores for their resistance against $P$. colocasiae. Co-culturing exploits the fact that endophytic fungi have evolved highly specialised capacities to occupy environments such as plants which always support dense populations of other microorganisms. Interactions between microorganisms lead to the activation of complex regulation mechanisms, which results in the biosynthesis of highly diverse natural products, such as secondary metabolites (phenol and tannins) and lytic enzymes (laccase) that are involved in host defence or symbiotic associations. Investigations into co-culture experiments with pathogen have been limited.

\section{Conclusion}

The main objective of this study was to evaluate in vitro the inhibitory effects of the endophytic fungi extracted from $L$. camara leaves on the mycelia growth of Phytophthora colocasiae the pathogen agents of Taro life blight.

The results of this study provide evidence that diverse groups of endophytic fungi are present in the leaves of $L$. camara and that these endophytes can be isolated and characterised. Five strains of endophytes were isolated and the strain coded $\mathrm{L}_{1}$ and $\mathrm{L}_{4}$ were not identified, while $\mathrm{L}_{2}, \mathrm{~L}_{3}$ and $\mathrm{L}_{5}$ could be identified as belonging to Clasdosporium sp. Among them, some were able to produce one or more phytochemical compounds (saponins, phenols, tannins and cardiac glycosides) and enzymes (laccase, amylase, protease, lipase and cellulose) which possess anti pathogenic properties. The fact that endophytic fungi lived in symbiotic relationship within the host plant and ensures its defence, the addition of their phytochemical compounds and enzymes produced by endophytes could have a perfect reaction against the pathogen. Perhaps, if they were associated, they might have an important and really visible effect on the $P$. colocasiae. The production of a large array of secondary metabolites by endophytic fungi is an interesting feature with potential practical applications. In this context, the strain $\mathrm{L}_{2}$ and $\mathrm{L}_{3}$ are a promising candidate for the biological control of taro leaf blight caused by $P$. colocasiae. This could then contribute to the preservation of the environment by means of an alternative to chemical fungicides by endophytic fungi producer of secondary metabolites.

\section{References}

[1] Onwueme I C. Tropical root and tuber crops - Production, perspectives and future prospects. FAO Plant Production \& Protection, Rome, 1994. 228 pp.

[2] Mbong G A, Fokunang C N, Lum FA, et al. An overview of Phytophthora colocasiae of cocoyams: A potential economic disease of food security in Cameroon. Discourse Journal of Agriculture and Food Sciences, 2013, 1 (9): 140-145.

[3] Davinder S, Grahame J, Hunter D, et al. A Threat to Food Security: Agriculture, 2012, 2 (3), 182-203.

[4] Qian Li, Rongjun Guo, Yujia Li, Wyatt H. Hartman, Shifang Li, Zhixiang Zhang, Susannah G. Tringe, Hongqing Wang. Insight into the Bacterial Endophytic Communities of Peach Cultivars Related to Crown Gall Disease Resistance. Appl. and Environ. Microbiol., 2019, 85 (9).

[5] Ruby E J, Bhavna VM and Raghunath T M. A review: Natural products from plant associated endophytic fungi. J. Microbiol. Biotech. Res., 2011, 1 (2): 21-32.

[6] Arnold AE., Mejia LC., Kyllo D, et al. Fungal endophytes limit pathogen damage in a tropical tree. Proceedings of the National Academy of Sciences of the United States of America, 2003, 100: $15649-15654$.

[7] Mbouobda HD, Fotso, Muyang RF, et al. Enzymes and qualitative phytochemical screening of endophytic fungi isolated from Lantana camara Linn. Leaves. Journal of Applied Biology and Biotechnology, 2014, 2 (06): 01-06.

[8] Sanjeeb K, Gaurav K, Loganathan K, et al. A Review on Medicinal Properties of Lantana camara Linn. Research Journal of Pharmacy and Technology, 2012, 5 (6): 711-715.

[9] Latha P, Anand T, Ragupathi N, et al. Antimicrobial activity of plant extracts and induction of systemic resistance in tomato plants by mixtures of PGPR strains and Zimmu leaf extract against Alternaria solani. Biology Control, 2009, 50: 85-93.

[10] Chung S, Kong H, Buyer JS, et al. Isolation and partial characterization of Bacillus subtilis ME488 for suppression of soilborne pathogens of cucumber and pepper. Apply Microbiology Biotechnology, 2008, 80: 115-123.

[11] Williams (2001) in: James B. Pawley Handbook of Biological Confocal Microscopy, third edition. 125P. 
[12] Hankin L. and Anagnostakis S L. The use of solid media for detection of enzyme production by fungi. Mycology, 1975, 67: 597-607.

[13] Stone J K, Polishook J D, White J R J. Endophytic fungi. In: G. Mueller, G. F. Bills and M. S. Foster (eds.), Biodiversity of fungi: inventory and monitoring methods, Elsevier, Burlington, MA, USA. 2004, 241-270.

[14] Shankar N B, Shashikala J, Krishnamurthy Y L. Diversity of fungal endophytes in shrubby medicinal plants of Malnad region, Western Ghats, southern India. Fungal Ecology, 2008, 1 89-93.

[15] Hayfa Jabnoun-Khiareddine, Nesrine Ibrahim, Rania Aydi Ben A., Messaoud M. and Mejda Daami-Remadi. Response of Tunisian Pomegranate (Punica granatum L.) Cultivars and Several Plant Hosts to Coniella granati (Saccardo). J. Horti., 2018, 5: 4.

[16] Figen Mert-Tÿrk. Saponins versus plant fungal pathogens. Journal of Cell and Molecular Biology, 2006, (13) 5: 13-17.

[17] Hari O, Anjana S, Nasser M. et al. Phytochemical screening and elemental analysis in different plant parts of Uraria picta Desv: A Dashmul species. Journal of chemistry and pharmaceutical Research, 2014, 6 (5): 756-760.

[18] Lorena Martínez, Julián Castillo, Gaspar Ros and Gema Nieto. Antioxidant and Antimicrobial Activity of Rosemary,
Pomegranate and Olive Extracts in Fish Patties. Antioxidants 2019, 8, 86; doi: 10.3390/antiox8040086.

[19] Sunitha V, Nirmala D, and Srinivas C. Extracellular Enzymatic Activity of Endophytic Fungal Strains Isolated from Medicinal Plants. World Journal of Agricultural Sciences, 2013, 9 (1): 01-09.

[20] Kavitha K. N., Ganesh S. G. and Sanjeev A. K. Enhanced biodegradation and kinetics of anthraquinone dye by laccase from an electron beam irradiated endophytic fungus. International Biodeterioration \& Biodegradation, 2018, 132: 241-250.

[21] Maria GL, Sridhar KR, Raviraja NS. Antimicrobial and enzyme activity of mangrove endophytic fungi of southwest coast of India. Journal of Agricultural Technology, 2005, 1: $67-80$.

[22] Orlandelli R, Tiago TD, Raiani NA, et al. Antifungal and proteolytic activities of endophytic fungi isolated from Piper hispidum Sw. Braz J Microbiol, 2015, 46 (2): 359-366.

[23] Abdel-Raheem A, Shearer C A. Extracellular enzyme production by freshwater ascomycetes. Fungal Divers, 2002, 11: 1-19.

[24] Omri MF, Castillo G, Parades SH, et al. Understanding and exploiting plant beneficial microbes. Current opinion in Plant Biology. 2017, 38: 155-163. 